\title{
How should doctors be employed?
}

\author{
Fiona Godlee editor in chief
}

The BMJ

\begin{abstract}
After last week's question about whether GPs should retain their gatekeeper role (doi:10.1136/bmj.i5272), this week we ask whether all GPs should become NHS employees in the same way hospital doctors are. With the bitter dispute between junior doctors in England and the government now entering a "cold war" (doi:10.1136/bmj.i5213), opting for direct NHS employment may seem like recklessness.

In our latest Head to Head debate Azeem Majeed is more positive about the proposition (doi:10.1136/bmj.i5064). Over a quarter of GPs in England are already salaried, but most of these are employed by other GPs or by commercial companies, often on worse terms than doctors employed by the NHS. Meanwhile, the way GP partners contract with the NHS contributes to their high levels of stress and dissatisfaction, he says, while failing to provide a proper career structure, and GPs become scapegoats for the NHS's problems.

But Laurence Buckman isn't giving up his self employed status any time soon. He relishes the distance from government that independent contractor status confers, and he claims that this makes him a more fearless advocate for his patients. An employed service would cost more and be less efficient, he says, while acknowledging that there is little good evidence to inform this debate.
\end{abstract}

There is, as always, a third way, articulated by Des Spence (doi:10.1136/bmj.15329). With his experience of building a large (35 000 patient) practice in Glasgow, he argues for a new contract and a new vision, requiring practices to become much larger, with groups of 20 or more doctors. All staff, including nurses and receptionists, should have a stake in the partnership, he says, and practices should be run as local not-for-profit social enterprises. This may sound utopian, but Spence says it's working, and, for my money, it looks worth trying out on a wider scale.

What of the rest of the NHS medical workforce in England? Will the health secretary's plans for more medical school places ease the pressure? I think so. But would it be right to require doctors trained in the NHS to repay some of the cost of training if they leave the service before four years (doi:10.1136/bmj. i5399)?

This seems to me like Jeremy Hunt shooting from the hip again, ripe with unforeseen consequences, playing to the public gallery while avoiding the many more fundamental issues affecting the NHS. We are at a dangerous tipping point, says Neena Modi (doi:10.1136/bmj.i5342), with the public largely unaware of the extent of change the NHS is undergoing, shielded from its consequences by the dedication of frontline staff. But, she says, "the painful political awakening of a generation of young doctors may ultimately prove the catalyst to find a way forward." 